\title{
Role of Glucocorticoids in Tuning Hindbrain Stress Integration
}

\author{
Rong Zhang (张蓉), ${ }^{1,3}$ Ryan Jankord, ${ }^{1}$ Jonathan N. Flak, ${ }^{1}$ Matia B. Solomon, ${ }^{1}$ David A. D'Alessio, ${ }^{1,2}$ \\ and James P. Herman ${ }^{1}$ \\ Departments of ${ }^{1}$ Psychiatry and ${ }^{2}$ Internal Medicine, University of Cincinnati, Cincinnati, Ohio 45237, and ${ }^{3}$ Division of Endocrinology, Children's Hospital \\ Boston, Harvard Medical School, Boston, Massachusetts 02115
}

The nucleus of the solitary tract (NTS) is a critical integrative site for coordination of autonomic and endocrine stress responses. Stress-excitatory signals from the NTS are communicated by both catecholaminergic [norepinephrine (NE), epinephrine (E)] and noncatecholaminergic [e.g., glucagon-like peptide-1 (GLP-1)] neurons. Recent studies suggest that outputs of the NE/E and GLP-1 neurons of the NTS are selectively engaged during acute stress. This study was designed to test mechanisms of chronic stress integration in the paraventricular nucleus, focusing on the role of glucocorticoids. Our data indicate that chronic variable stress (CVS) causes downregulation of preproglucagon (GLP-1 precursor) mRNA in the NTS and reduction of GLP-1 innervation to the paraventricular nucleus of the hypothalamus. Glucocorticoids were necessary for preproglucagon (PPG) reduction in CVS animals and were sufficient to lower PPG mRNA in otherwise unstressed animals. The data are consistent with a glucocorticoid-mediated withdrawal of GLP-1 in key stress circuits. In contrast, expression of tyrosine hydroxylase mRNA, the rate-limiting enzyme in catecholamine synthesis, was increased by stress in a glucocorticoid-independent manner. These suggest differential roles of ascending catecholamine and GLP-1 systems in chronic stress, with withdrawal of GLP-1 involved in stress adaptation and enhanced NE/E capacity responsible for facilitation of responses to novel stress experiences.

\section{Introduction}

Hindbrain neurons in the nucleus of the solitary tract (NTS) represent an important waystation in processing of stressful stimuli. These neurons initiate physiological responses through projections to the hypothalamic paraventricular nucleus (PVN) and preautonomic effector systems (such as the rostral ventrolateral medulla), resulting in secretion of glucocorticoids and activation of the autonomic nervous system (cf. Plotsky et al., 1989; UlrichLai and Herman, 2009). The critical role of NTS relays in stress responding is underscored by a strong linkage between ascending noradrenergic neurons and generation of glucocorticoid release after acute challenge (Plotsky, 1987; Szafarczyk et al., 1987). Emerging evidence also supports a role for noncatecholaminergic, glucagon-like peptide-1 (GLP-1) NTS neurons in stress stimulation of hypothalamo-pituitary-adrenal (HPA) axis and autonomic regulation, suggesting the existence of multiple stress-integrative pathways from this important hindbrain locus (Kinzig et al., 2002, 2003).

Catecholamines and GLP-1 are produced in different cells that comprise the two major populations of stress-responsive

Received Jan. 15, 2010; revised March 17, 2010; accepted June 20, 2010.

This work was supported by National Institutes of Health Grants MH069860 (J.P.H. and D.A.D.) and MH049698 (J.P.H.). We thank Dr. Yve Ulrich-Lai for assistance with ADX surgeries and helpful discussion and Kenneth Jones and Ingrid Thomas for technical assistance.

Correspondence should be addressed to either of the following: Dr. James P. Herman, Department of Psychiatry, University of Cincinnati, 2170 East Galbraith Road, Cincinnati,OH 45237-0506, E-mail: james.herman@uc.edu; or Dr. Rong Zhang, Division of Endocrinology, Children's Hospital Boston, Harvard Medical School, 300 Longwood Avenue, Boston, MA 02115, E-mail: rong.zhang@childrens.harvard.edu.

DOI:10.1523/JNEUROSCI.0522-10.2010

Copyright $\odot 2010$ the authors $\quad 0270-6474 / 10 / 3014907-08 \$ 15.00 / 0$ neurons in the NTS (Larsen et al., 1997). Moreover, norepinephrine/epinephrine (NE/E) neurons appear to be preferentially involved in generating responses to homeostatic challenge (Gaillet et al., 1991; Ritter et al., 2003), whereas GLP-1 neurons mediate HPA axis responses to both psychogenic and homeostatic stressors (Kinzig et al., 2003). Together, the data suggest that NE/E and GLP-1 neurons have distinct roles in CNS regulation of stress responses.

Appropriate regulation of stress responding requires the capacity for integration over time. Acute, "one-time" stress responses are critical for short-term survival and are efficiently initiated and terminated by neuronal drive and glucocorticoid negative feedback (Herman and Cullinan, 1997; Ulrich-Lai and Herman, 2009). Prolonged or intermittent stress represents a significant temporal challenge that engages mnemonic systems to fuel long-term changes that can be adaptive or, in many cases, maladaptive. Previous studies indicate that neural governance of stress responses shifts significantly during exposure to chronic drive, resulting in recruitment and derecruitment of neural pathways (Marti et al., 1994; Schulkin et al., 1994; Dallman et al., 2003). Reorganization of stress signaling circuitry appears to underlie habituation and sensitization of effector pathways, including the HPA axis.

Noradrenergic and GLP-1-containing terminals heavily innervate the hypophysiotrophic as well as autonomic zones of the PVN, underscoring the importance of these two neurotransmitters in stress processing (Sawchenko and Swanson, 1981; Liposits et al., 1986; Sarkar et al., 2003; Tauchi et al., 2008a). These neurons are subject to descending inputs from structures such as the 
infralimbic cortex and central amygdaloid nucleus (Schwaber et al., 1982; Vertes, 2004), regions thought to be recruited during chronic stress drive (Dallman et al., 2003; Ulrich-Lai and Herman, 2009). Moreover, neurons in the NTS contain both glucocorticoid and mineralocorticoid receptors (Ahima and Harlan, 1990; Geerling et al., 2006), with evidence for colocalization of glucocorticoid receptors with catecholaminergic markers (Uht et al., 1988). The latter suggests that stress-induced glucocorticoid secretion may modulate NTS function.

The centrality of the NTS in stress initiation makes it a potentially important node in processes regulating stress adaptation and/or maladaptation. In the current study, we document different patterns of stress plasticity in catecholaminergic and GLP-1 containing NTS cell populations after chronic stress or glucocorticoid exposure, providing evidence for differential involvement of these two important hindbrain pathways in control of chronic stress responses.

\section{Materials and Methods}

Animals. Adult male Sprague Dawley rats (Harlan Sprague Dawley) weighing 250-300 g were housed two rats per cage with ad libitum access to rat chow and water. All animals were maintained on a $12 \mathrm{~h} \mathrm{light/dark}$ cycle in a temperature- and humidity-controlled vivarium, with lights on from 6:00 A.M. to 6:00 P.M. Animals were maintained in accordance with the National Institutes of Health Guide for the Care and Use of Laboratory Animals (1996). All animal procedures were approved by the Institutional Animal Care and Use Committee at the University of Cincinnati.

Chronic variable stress procedure. Animals were stressed with our standard chronic variable stress (CVS) procedure for 2 weeks (supplemental Table 1, available at www.jneurosci.org as supplemental material). After completion of the CVS paradigm (day 15), rats were killed by decapitation on the following morning. Trunk blood and adrenal and thymus glands were collected for additional analysis or measurement. For in situ hybridization and quantitative real-time PCR (QRT-PCR), removed brains were immersed into isopentane cooled on dry ice $\left(-45^{\circ} \mathrm{C}\right)$ and stored at $-80^{\circ} \mathrm{C}$ until further procedure. For immunohistochemistry (IHC), animals were treated with the same CVS schedule noted above. After completion of the CVS paradigm (day 15), animals were anesthetized and perfused with $100 \mathrm{ml}$ of $0.9 \%$ saline, followed by $4 \%$ paraformaldehyde as described previously (Zhang et al., 2009).

CVS in adrenalectomized corticosterone-replaced rats. Bilateral adrenalectomies were performed under anesthesia $(87 \mathrm{mg} / \mathrm{kg}$ ketamine, 13 $\mathrm{mg} / \mathrm{kg}$ xylazine), and the surgical specimens were examined immediately to ensure complete excision of the adrenal glands. Sham adrenalectomized (ADX) animals had identical surgical procedures with the exception of adrenal removal. ADX animals were provided with $0.9 \%$ saline to replace depleted sodium secondary to the loss of aldosterone, with corticosterone (30 $\mu \mathrm{g} / \mathrm{ml}$; Sigma-Aldrich) provided in the $0.9 \%$ drinking saline. Corticosterone was initially dissolved in ethyl alcohol (EtOH) and diluted to a final concentration of $30 \mu \mathrm{g} / \mathrm{ml}$ in saline with $0.2 \% \mathrm{EtOH}$. Sham rats were provided with $0.2 \% \mathrm{EtOH}$ in their drinking water. Three days after surgery, blood samples were collected by tail nick from freely moving rats within $2 \mathrm{~h}$ of lights on (basal nadir corticosterone level) and $2 \mathrm{~h}$ of lights off (basal peak corticosterone level) to determine unstressed corticosterone levels. After 1 week recovery from surgery, animals were assigned to four groups including sham control, sham CVS, ADX control, and ADXCVS. Rats were exposed to our standard CVS paradigm as described above for 2 weeks and killed by decapitation the morning after the last afternoon stress exposure $(\sim 16 \mathrm{~h})$. Trunk blood, brains, thymi, and adrenals (sham rats) were collected and treated as described above for additional analysis.

Regulation of PPG and tyrosine hydroxylase gene expression by exogenous corticosterone. The regulation of tyrosine hydroxylase (TH) and PPG gene expression by glucocorticoids were tested using twice-daily injection of corticosterone $(3.5 \mathrm{mg} / \mathrm{kg} / \mathrm{ml}$ in propylene glycol vehicle; Sigma-Aldich) for two weeks (9:00-10:00 A.M. and 3:00-4:00 P.M., which mirrored our standard CVS schedule). Vehicle groups were given injections of propylene glycol. Rats were killed by decapitation in the following morning after the last P.M. injection. Trunk blood, thymi, adrenal, and brains were collected and stored as described above for additional analysis. To confirm the plasma corticosterone levels induced by a single injection, blood samples were collected in freely moving rats at $10,30,60$, and $120 \mathrm{~min}$ after the initial subcutaneous administration, and plasma corticosterone was determined by radioimmunoassay (RIA). The time points of blood collection were determined to match the time course of stress-induced plasma corticosterone determinations typically used in our acute stress designs (Zhang et al., 2009).

In situ hybridization. In situ hybridization was performed as described previously (Zhang et al., 2009). Briefly, antisense cRNA probes complementary to rat PPG (399 bp) and TH (366 bp) were used for in situ hybridization. The TH DNA construct was cloned into pCR 4-TOPO vector, linearized with SpeI, and transcribed with T3 RNA polymerase. The final concentration of the in vitro transcription reactions were as follows: $1 \times$ transcription buffer, $1.5-2.5 \mu \mathrm{g}$ of linearized DNA fragment, $330 \mu \mathrm{M}$ ATP, $330 \mu \mathrm{M}$ GTP, $330 \mu \mathrm{M}$ CTP, $10 \mu \mathrm{M}$ UTP, $62.5 \mu \mathrm{Ci}$ of $\left[{ }^{35} \mathrm{~S}\right]$ UTP, $66.6 \mathrm{~mm}$ dithiothreitol, $40 \mathrm{U}$ of RNase inhibitor, and $20 \mathrm{U}$ of the T7 or T3 RNA polymerase. The transcription reactions were incubated at $37^{\circ} \mathrm{C}$ for $1 \mathrm{~h}$, and the labeled probes were separated from free nucleotides by ammonium acetate precipitation and reconstituted in diethylpyrocarbonate-treated nanopure water. The probes were labeled by in vitro transcription using $\left[{ }^{35} \mathrm{~S}\right] \mathrm{UTP}$, with prehybridization and posthybridization protocols conducted as described previously (Zhang et al., 2009).

Hybridized slides were exposed on Kodak Biomax MR-2 film (Eastman Kodak) for 3 weeks for PPG and for $10 \mathrm{~d}$ for TH. Hybridizations with sense probe were used as specificity controls. ARC $146-{ }^{14} \mathrm{C}$ standard slides (American Radiolabeled Chemicals) were used to construct standard curves, so as to verify that all signal intensities were in the linear range of detection.

Assessment of NTS mRNA expression was performed using the guidance of the Paxinos and Watson (2005) rat brain atlas. Images were captured from in situ hybridization autoradiographs using a High Performance CCD camera (Cohu) and Image 1.62 software (Scion). Semiquantitative analysis was conducted on every fifth brain section containing the anatomical region of interest. Mean gray level (signal) was quantified bilaterally in the NTS by subtracting the gray level signal over a nonhybridized area of tissue (white matter) and expressed as corrected gray level. The mean corrected gray level values were calculated for each animal and used in the statistical analysis in a blinded manner.

QRT-PCR. The NTS was isolated according to previously published methods (Zhang et al., 2009). Briefly, using the obex (bregma, -14.40 $\mathrm{mm}$ ) and the fourth ventricle as landmarks, the NTS was isolated from the anterior (rostral) margin (bregma, $\sim 11.04 \mathrm{~mm} ; 3.36 \mathrm{~mm}$ from obex to rostral margin) to the posterior (caudal) margin (bregma, $\sim 15.72$ $\mathrm{mm} ; 1.32 \mathrm{~mm}$ from obex to caudal margin). Both sides were trimmed $\sim 1$ $\mathrm{mm}$ along the brain edges, and an additional cut was made $\sim 2 \mathrm{~mm}$ ventral to the dorsal surface of caudal brainstem. The NTS dissections were stored in RNAlater (Ambion) at $4^{\circ} \mathrm{C}$ until RNA extraction.

NTS dissections were homogenized in Tri-reagent (Molecular Research Center), and total RNA was isolated following the manufacturer's instructions. RNA samples were treated by Turbo DNA-free (Ambion) to remove genomic DNA. cDNAs were synthesized (SuperScriptTM III First-Strand Synthesis System; Invitrogen) according to the manufacturer's instruction. Primer sequences for PPG heteronuclear RNA (hnRNA), PPG mRNA, and the housekeeping gene $L$-32 were used as described previously (Zhang et al., 2009). TH primer sequences were designed using Primer3 software (Rozen and Skaletsky, 2000) and synthesized by Sigma-Aldrich (supplemental Table 2, available at www. jneurosci.org as supplemental material).

QRT-PCR analysis was performed in the iCycler iQ Multi-Color Real Time PCR Detection System (Bio-Rad). cDNA amounts present in each sample were determined using iQ SYBR Green Supermix (Bio-Rad). Threshold cycle readings for each of the unknown samples were used, and the results were transferred and calculated in Excel using the $\Delta \Delta \mathrm{Ct}$ method (Livak and Schmittgen, 2001). Negative RT samples were in- 
cluded to rule out genomic DNA contamination, and amplicons of different primers were verified by electrophoresis (supplemental Fig. 1, available at www.jneurosci.org as supplemental material).

Immunohistochemistry. For GLP-1 staining in the NTS, sections were pretreated for antigen retrieval $\left(0.01 \mathrm{M}\right.$ citrate buffer for $30 \mathrm{~min}$ at $80^{\circ} \mathrm{C}$, pH 6.0), and IHC was performed as described previously (Huo et al., 2006). Free-floating sections were incubated with a rabbit anti-GLP-1 antibody (diluted 1:1000; Peninsula Laboratories) overnight. In our hands, this antibody provides optimal visualization of GLP-1 cell bodies in the hindbrain. Sections were rinsed five times for $5 \mathrm{~min}$ in $50 \mathrm{~mm}$ potassium PBS (KPBS) and transferred into Cy3-labeled donkey anti-rabbit secondary antibody (1: 500; Jackson ImmunoResearch) for $1 \mathrm{~h}$. Sections were then rinsed five times for $5 \mathrm{~min}$ in KPBS, mounted onto slides, and coverslipped with Gelvitol.

Hypothalamic sections were incubated in a mouse monoclonal antiGLP-1 antibody, which is specific for intact GLP-1 [7-36], overnight at $4^{\circ} \mathrm{C}$ (diluted $1: 10,000$ ). In our hands, this antibody provides optimal visualization of GLP-1 axons and terminals (Tauchi et al., 2008a). Sections were rinsed five times for $5 \mathrm{~min}$ in KPBS and subsequently incubated in biotinylated goat anti-mouse secondary antibody (diluted 1:500; Vector Laboratories) for $1 \mathrm{~h}$. Following five 5 min rinses in KPBS, sections were incubated in avidin-biotin complex (diluted 1:1000; Vector Laboratories) for 1 additional hour. Sections were rinsed five times for 5 min in KPBS, incubated in biotin-labeled tyramide (diluted 1:250; PerkinElmer Life Sciences), rinsed five times for $5 \mathrm{~min}$, and incubated in Cy3-conjugated streptavidin (diluted 1:500; Jackson ImmunoResearch) for $30 \mathrm{~min}$. To verify hypothalamic depletion of GLP-1, IHC was performed on an additional series of hypothalamic sections from the same animals, using a different primary antibody, enteroglucagon C-terminal octapeptide (EGCO; diluted 1:5000) (Collie et al., 1994). The EGCO antibody recognizes a different cleavage product of proglucagon (oxyntomodulin) (Collie et al., 1994). Biotinylated goat anti-rabbit secondary antibody (1:500; Vector Laboratories) was used as a secondary antibody, and tissue was also processed for immunofluorescence using procedures outlined above.

For NTS TH IHC, NTS sections were rinsed in $50 \mathrm{~mm}$ KPBS and incubated overnight with rabbit anti-TH primary antibody (diluted 1:1500; Millipore). The next day, sections were incubated with Cy3labeled donkey anti-rabbit secondary antibody (diluted 1:500; Jackson ImmunoResearch) for $1 \mathrm{~h}$ and visualized by fluorescence microscopy.

Image collection and processing. All sections in the series were then examined by fluorescent microscopy to identify positive labeled cells and fibers. Images of the NTS were captured from low magnification to high magnification with a digital camera (AxioCam; Carl Zeiss) connected to a microscope (Axio-observer; Carl Zeiss). In $20 \times$ images, TH- and GLP1 -immunoreative positive cells were individually selected, and fluorescence intensity was measured using AxioVision Rel. 4.6 software (Carl Zeiss). Background was determined from equivalent unstained areas in each tissue section. The corrected densitometric signal was calculated by subtracting the background fluorescence from each cellular determination. All analyses were conducted by observers blind to the treatment conditions. The anatomical position of sections was determined from $5 \times$ images, based on Paxinos and Watson (2005) coordinates.

Imaging of PVN GLP-1 and EGCO fiber density was performed using AxioVision Rel. 4.6 software. Images were captured using a 510 Meta laser confocal microscope system in single-channel mode (Zeiss), as described previously (Zhang et al., 2009). All confocal images processed for analysis were collected using a $40 \times$ oil-immersion lens with a numerical aperture of 1.5 at high-capture resolution (image size, $1024 \times 1024$ pixels). The images of the medial parvocellular division of the PVN (mpPVN) were collected, and $Z$-stack images were converted to three-dimensional projections using Zeiss LSM 510 Image Browser software. The field area percentage occupied by proglucagon-derived peptide immunoreactivity was determined using the measurement function of AxioVision 4.6 software (Zeiss), using methods previously established in our laboratory (Flak et al., 2009). Field areas were averaged across animals.

RIA. Plasma corticosterone levels were determined by RIA using ${ }^{125} \mathrm{I}$ RIA kits from MP Biomedicals. All plasma samples were analyzed in duplicate, and plasma corticosterone measures from a single experiment were undertaken in the same RIA analysis to avoid interassay variability. For the corticosterone RIA, the intraassay coefficient of variation was $8 \%$.

Statistical analysis. All results are given as the mean \pm SEM. In situ hybridization, IHC, and RIA data obtained from the standard CVS experiment were analyzed by one-way ANOVA with StatView (SAS Institute), and significant main effects were also analyzed by the PLSD post hoc test. GLP-1 and EGCO staining data were expressed as the percentage of area occupied by immunoreactivity fiber in total measured areas. For QRT-PCR analysis, $L$-32, a housekeeping gene, was applied as a reference gene to normalize the data. Values were calculated using $L-32$ as an internal standard. PPG and TH hnRNA and mRNA data were expressed as a percentage of control and analyzed by one-way ANOVA followed by Fisher's PLSD post hoc test to distinguish among groups. For ADX CVS experiments, data were calculated as described above, and statistical analyses were undertaken by two-way ANOVA [adrenalectomizedcorticosterone replaced (ADX-Cort), stress] with GB Stat version 9.0 (Dynamic Microsystems), with significant main effects or interactions followed up with Fisher's LSD post hoc tests. Statistical significance was set at $p<0.05$.

\section{Results}

\section{Effectiveness of the CVS paradigm}

The CVS protocol uses random, unpredictable exposure to multiple stressors to produce a reliable constellation of physiological end points. CVS reduced the bodyweight gain at day 7 (control, $29.889 \pm 2.248 \mathrm{~g}$; CVS, $12.882 \pm 1.755 \mathrm{~g}$ ) and day 14 (control, $52.278 \pm 3.974$ g; CVS, $25.824 \pm 2.982 \mathrm{~g} ; p<0.001$ ). CVS exposure elevated the basal nadir plasma corticosterone (control, $27.59 \pm 1.24 \mathrm{ng} / \mathrm{ml}$; CVS, $85.77 \pm 8.71 \mathrm{ng} / \mathrm{ml} ; p<0.01$ ), which is consistent with previous reports (Herman et al., 1995). Both actual thymi weight (control, $523.305 \pm 26.304 \mathrm{mg}$; CVS, $424.650 \pm 14.486 \mathrm{mg} ; p<0.001)$ and adjusted thymi weight [actual thymi weight (milligrams)/bodyweight $($ grams $) \times 100$; control, $163.872 \pm 8.554$; CVS, $141.327 \pm 4.664 ; p<0.03$ ] were decreased by CVS. CVS increased both actual adrenal weights (control, $49.485 \pm 0.939 \mathrm{mg}$; CVS, $53.090 \pm 1.260 \mathrm{mg} ; p<0.05$ ) and adjusted adrenal weights (control, $15.469 \pm 0.288 \mathrm{mg}$; CVS, $17.691 \pm 0.446 \mathrm{mg} ; p<0.01)$. The observed thymic atrophy and adrenal hypertrophy are consistent with increased cumulative adrenocorticotropic hormone (ACTH) and glucocorticoid exposure, which are hallmarks of the CVS model (Ulrich-Lai et al., 2006).

\section{CVS differentially regulates NTS peptidergic and catecholaminergic neurons}

In the brainstem, PPG mRNA expression is confined to noncatecholaminergic neurons in the NTS and mediolateral medulla (Larsen et al., 1997). When analyzed by in situ hybridization, expression of PPG mRNA decreased after CVS exposure in NTS $\left(F_{(1,8)}=38.506 ; p<0.01\right)$ (Fig. $\left.1 a, b, e\right)$. In contrast, NTS expression of TH mRNA was significantly augmented after CVS $\left(F_{(1,9)}=\right.$ 13.945; $p<0.01$ ) (Fig. $1 c, d, f)$. The in situ hybridization results were confirmed by QRT-PCR analysis (PPG mRNA: $F_{(1,13)}=$ 9.877, $p<0.01$; TH mRNA: $F_{(1,10)}=9.05, p<0.01$ ) (Fig. $\left.2 a, c\right)$.

Transcription of PPG and TH genes was estimated by assessment of poststress hnRNA expression, using quantitative PCR amplification of intronic sequences (intron D of the PPG primary transcript, intron 3 of the TH primary transcript). In contrast to expression of the mature message, PPG hnRNA expression was elevated after CVS $\left(F_{(1,8)}=13.57 ; p<0.01\right)$ (Fig. $\left.2 b\right)$. Expression of TH hnRNA was also elevated by CVS $\left(F_{(1,11)}=7.72 ; p<0.01\right)$ (Fig. $2 d$ ), consistent with chronic stress-induced drive of TH production at the level of gene transcription.

Changes in PPG and TH mRNA expression suggest altered availability of neuropeptide/neurotransmitters in circuitry re- 

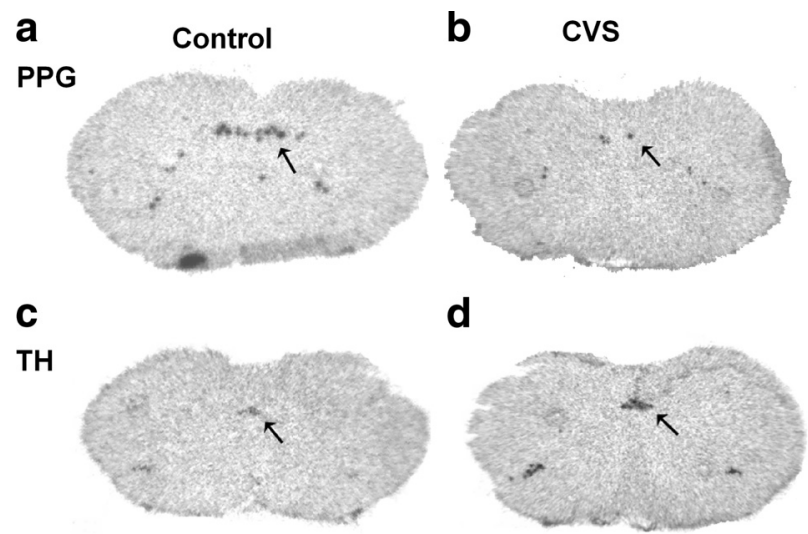

d

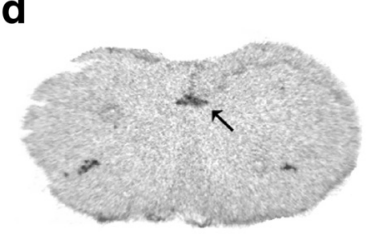

e

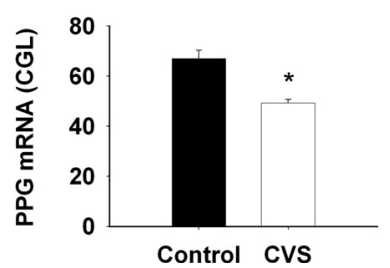

f

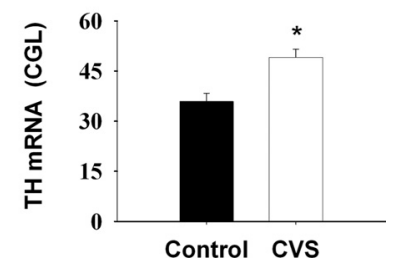

Figure 1. CVS exposure affected the both PPG and TH mRNA expression in the NTS. $\boldsymbol{a}-\boldsymbol{d}$, Representative images for PPG mRNA and TH mRNA expression in the NTS. Left, Control; right, CVS. $\boldsymbol{e}, \boldsymbol{f}$, Semiquantitative results showed that CVS exposure declined PPG mRNA expression, whereas it enhanced TH mRNA expression in NTS. ${ }^{*} p<0.01$ versus control.
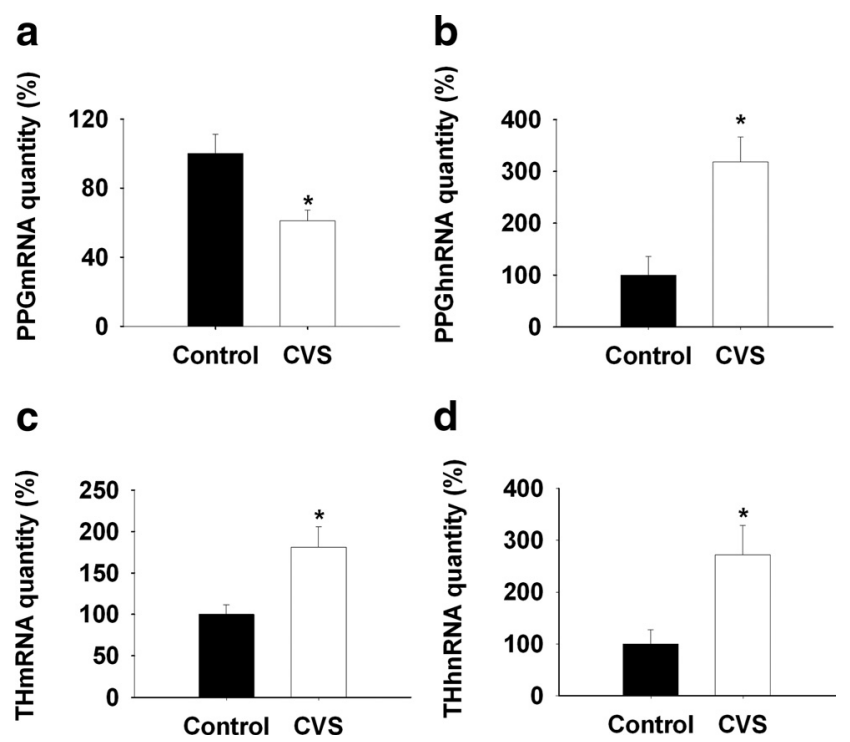

Figure 2. $\quad$ RTT-PCR analysis of the regulation of NTS PPG and TH transcription by CVS exposure. $\boldsymbol{a}, \boldsymbol{b}$, NTS PPG mRNA expression decreased while PPG hnRNA expression increased by 2 week CVS exposure compared with control. $\boldsymbol{c}, \boldsymbol{d}$, Prolonged stress exposure elevated TH mRNA and hnRNA expression in NTS compared with the naive control. ${ }^{*} p<0.01$ versus control.

sponsible for long-term stress reactivity. To assess this possibility, we evaluated GLP-1 innervation of the medial parvocellular zone of the PVN after CVS. Our analysis revealed significant decreases in the density of GLP-1-immunoreactive fibers and terminals in the PVN after CVS $\left(F_{(1,12)}=5.38 ; p<0.05\right)$ (Fig. 3). To provide additional verification of PPG-derived peptide depletion in the PVN, we also assessed fiber density using a second antibody, which identified a cocleaved PPG product, oxyntomodulin. Depletion of staining was identical to that seen using the anti-GLP-1 antibody (supplemental Fig. 2, available at www.jneurosci.org as supplemental material).

We also evaluated GLP-1 and TH immunoreactivity in the caudal medulla, using fluorescence densitometry. Cellular expression of GLP-1 immunoreactivity was substantially reduced in NTS neurons after CVS $\left(F_{(1,11)}=7.70 ; p<0.05\right)$ (Fig. $\left.4 a-e\right)$. Decreases in GLP-1 were specific to cells situated caudal (bregma, -14.52 ) to the obex (bregma, -14.40 ). In contrast, TH immunoreactivity was selectively enhanced in NTS neurons located rostral (bregma, -14.28$)$ to the obex $\left(F_{(1,12)}=6.48, p<0.05\right)($ Fig. $4 f-j)$. As reported previously, no GLP-1/TH colocalization was observed in the NTS (data not shown). Together, the data confirm that CVS modulation of mRNA levels are also manifest as changes in peptide/ transmitter and suggest that CVS-responsive PPG and TH neurons are compartmentalized to different regions of the NTS.

\section{Stress-induced glucocorticoids secretion is necessary for NTS PPG mRNA down-regulation}

Subsequent studies explored the role of CVS-induced glucocorticoid secretion in modulation of PPG and TH mRNA/hnRNA expression. To assess the necessity of glucocorticoids in gene regulation, we used an ADX-Cort replacement model that affords maintenance of physiological glucocorticoid availability across the day-night cycle by providing exogenous corticosterone in the drinking water. Our data indicate resting A.M. and P.M. corticosterone levels did not differ between the ADX-Cort replacement group and sham-ADX rats (Fig. 5a). As expected, exposure to CVS did not alter resting A.M. corticosterone in the ADX-Cortreplaced group (main effect of surgery: $F_{(1,27)}=48.70, p<0.01$; main effect of CVS: $F_{(1,27)}=64.40, p<0.01$; surgery $\times$ CVS interaction: $F_{(1,27)}=53.65, p<0.01$ ) (Fig. 5b). Sham ADX animals showed the standard indices of CVS-induced HPA axis upregulation (increased resting corticosterone, thymic atrophy, adrenal hypertrophy) (supplemental Fig. 3, available at www.jneurosci.org as supplemental material).

Analysis of PPG and TH gene regulation revealed a differential effect of CVS-induced glucocorticoid secretion on the two brainstem stress systems. In the case of PPG, downregulation of PPG mRNA and upregulation of PPG hnRNA were completely blocked in ADX-replaced rats, which did not have twice-daily fluctuations in corticosterone levels in response to CVS stressors. There was a significant surgery-CVS interaction $\left(F_{(1,23)}=4.19\right.$; $p<0.05)$ but no main effect of surgery or CVS, suggesting that lack of glucocorticoid response to stress blocked the effect of CVS on the initiation of PPG transcription (Fig. $5 c, d$ ). In contrast, ADX replacement had no significant impact on NTS TH mRNA or hnRNA expression $\left(\mathrm{CVS}: F_{(1,8)}=17.28, p<0.05\right)($ Fig. $5 e, f)$.

\section{Exogenous glucocorticoids are sufficient for NTS PPG mRNA downregulation}

Next, we tested whether chronic episodic elevations in glucocorticoids were sufficient to modulate PPG or TH mRNA/hnRNA expression in the NTS in the absence of concurrent stress. Chronic intermittent injections of exogenous corticosterone decreased PPG mRNA expression, similar to that seen after CVS $\left(F_{(1,19)}=9.003 ; p<0.01\right.$ ) (Fig. 6a). However, PPG hnRNA was also decreased by chronic glucocorticoid treatment, indicating that glucocorticoids and stress may interact in regulation of PPG transcription $\left(F_{(1,18)}=12.56 ; p<0.01\right.$ ) (Fig. 6b). Notably, chronic glucocorticoid exposure did not alter either TH mRNA or hnRNA (Fig. $6 c, d$ ).

Our studies indicate that subcutaneous injection of corticosterone at a dose of $3.5 \mathrm{mg} / \mathrm{kg}$ is sufficient to emulate a physiological 


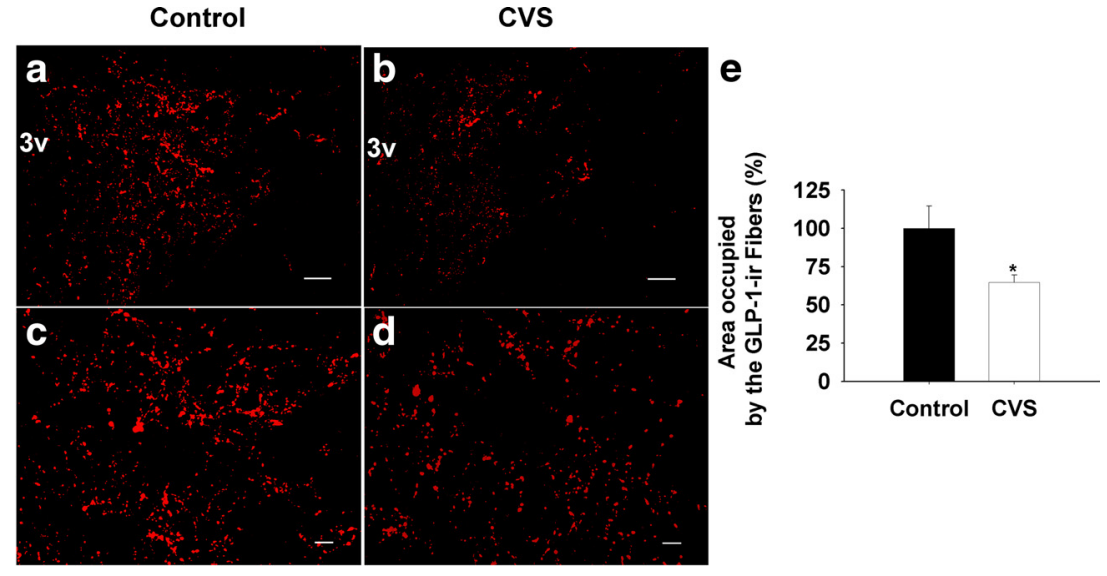

Figure 3. Quantification of the expression of GLP-1 fiber in the mpPVN after 2 weeks of CVS exposure. The field area occupied by GLP-1-immunoreactive positive fibers was determined and expressed as a percentage of total measured area (FIdAreaP). Data are shown as percentage of control. $\boldsymbol{a}, \boldsymbol{b}$, Representative images for low-magnification GLP-1 fiber staining in the PVN. mpPVN, Medial parvocellular PVN; $3 v$, third ventricle. $\boldsymbol{c}, \boldsymbol{d}$, Representative images for high magnification of projection images. Left, Control; right, CVS. e, Quantification of the expression of GLP-1 fiber in the mpPVN after CVS exposure. The percentage of area occupied by GLP-1-positive fibers declined after 2 weeks of CVS exposure compared with the control. Scale bars: $\boldsymbol{a}, \boldsymbol{b}, 100 \mu \mathrm{m} ; \boldsymbol{c}, \boldsymbol{d}, 20 \mu \mathrm{m} .{ }^{*} p<0.05$ versus control.

\section{GLP-1}
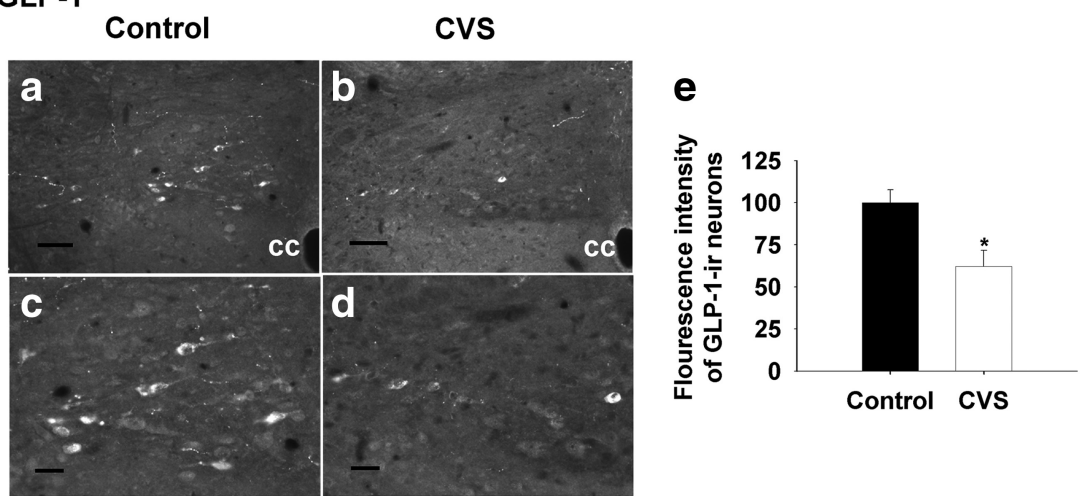

TH
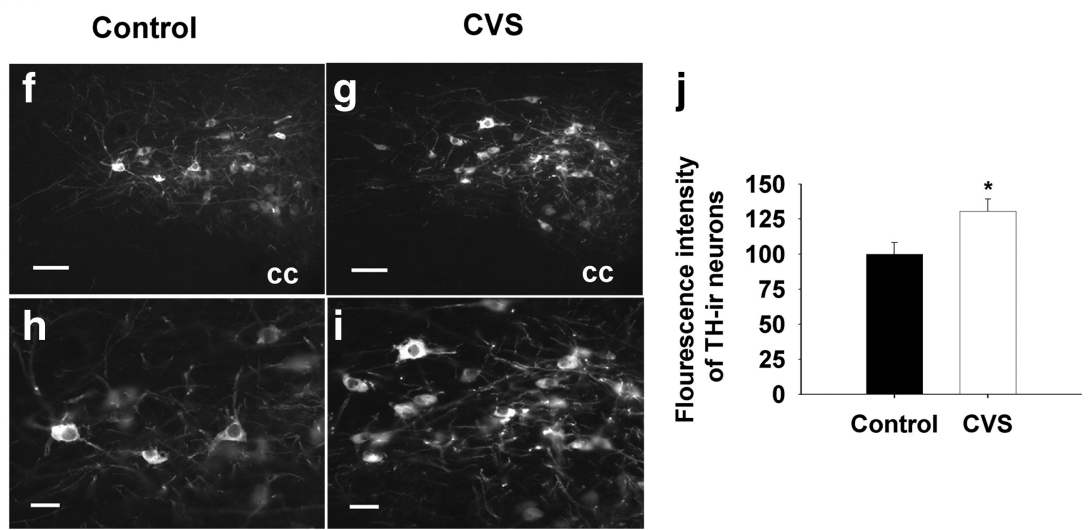

Figure 4. Quantification of the densitometrics of GLP-1- and TH-immunoreactive positive neurons in the NTS after 2 weeks of CVS exposure. $\boldsymbol{a}-\boldsymbol{d}, \boldsymbol{f}-\boldsymbol{i}$, Representative images of GLP-1- and TH-immunoreactive positive staining at the level of bregma (-14.40); lowmagnification images are shown at the top, and high-magnification images are shown at the bottom. Left, Control; right, CVS. e, Decrement of the densitometrics of NTS GLP-1-immunoreactive positive neurons in the CVS-treated rats compared with the control group. $\boldsymbol{j}$, Increment of densitometrics of NTS TH-immunoreactive positive neurons in the CVS-treated rats compared with the control animals. Data are shown as the percentage of control. cc, (entral canal. Scale bars: $\boldsymbol{a}, \boldsymbol{b}, \boldsymbol{f}, \boldsymbol{g}, 50 \mu \mathrm{m} ; \boldsymbol{c}, \boldsymbol{d}, \boldsymbol{h}, \boldsymbol{i}, 20 \mu \mathrm{m} .{ }^{*} p<0.05$ versus control.

stress response, with corticosterone rising within $10 \mathrm{~min}$ and attaining peak levels at $30 \mathrm{~min}$, comparable to an acute stressinduced plasma corticosterone surge. There were main effects of $\operatorname{drug}\left(F_{(1,63)}=349.92 ; p<0.01\right)$ and time $\left(F_{(3,63)}=53.09 ; p<0.01\right)$, as well as a significant drug $\times$ time interaction $\left(F_{(3,63)}=22.31 ; p<0.01\right)$ (Fig 6. e). Thymus weight and adrenal weight were both decreased by corticosterone injection (supplemental Fig. 4, available at www.jneurosci.org as supplemental material), consistent with enhanced glucocorticoid availability and reduced ACTH release subsequent to enhanced exogenous feedback. These data are in agreement with previous reports (Young et al., 1995).

\section{Discussion}

The results of this study document divergent regulation of brainstem GLP-1 and $\mathrm{NE} / \mathrm{E}$ neurons after chronic stress exposure. Exposure to chronic stress significantly reduced PPG mRNA expression in a glucocorticoid-dependent fashion, indicating that stress-induced glucocorticoid release produces long-term PPG downregulation. In contrast, $\mathrm{TH}$ mRNA and initial gene transcription increased after CVS in a glucocorticoid-independent fashion. Differential chronic stress regulation of two putative stress-excitatory systems is consistent with selective involvement in different aspects of stress regulation.

Previous work by our group demonstrated downregulation of PPG mRNA, upregulation of PPG hnRNA, and decreased PVN GLP-1 fiber staining after acute stressors. In our previous study, PPG mRNA/hnRNA expression returned to normal levels within $2 \mathrm{~h}$ of stress cessation, suggesting that transcriptional drive initiated by the stress exposure repleted mature PPG mRNA fairly quickly (Zhang et al., 2009). The current study suggests that chronic stress causes downregulation of NTS PPG mRNA and PVN GLP-1 fiber staining that persists at least $16 \mathrm{~h}$ after cessation of the last stressor, suggesting longlasting rather than transient reductions in PPG action in the CNS after CVS. Since PPG hnRNA was increased by CVS, the data are consistent with cumulative effects of repeated stress on factors influencing steady-state PPG mRNA levels.

Our studies suggest glucocorticoids as causal factors in long-term PPG downregulation. Adrenalectomy with physiological replacement blocked the ability of chronic stress to decrease PPG mRNA expression, whereas twice-daily administration of corticosterone was sufficient to drive down PPG mRNA expression in the absence of concurrent stress. These data suggest that cumulative or episodic exposures to stress-induced glucocorticoid elevations are necessary and sufficient to downregulate PPG gene expression in a long-term fashion. Glucocorticoids are known to regulate RNA stability through binding to and facilitating mRNA 
a

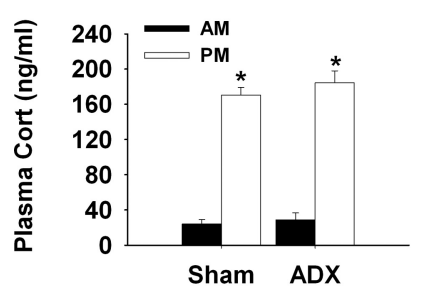

C
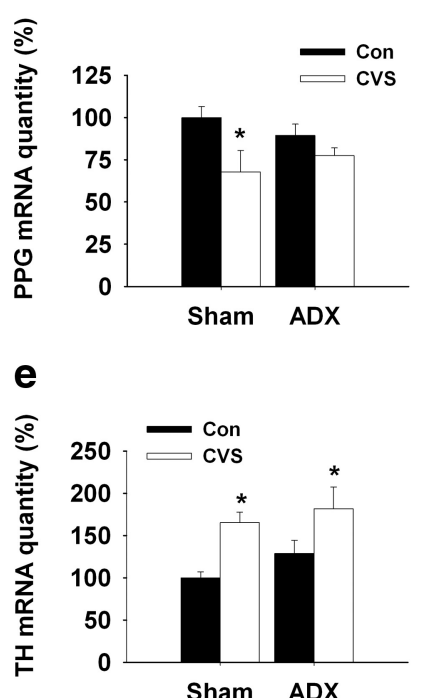

b

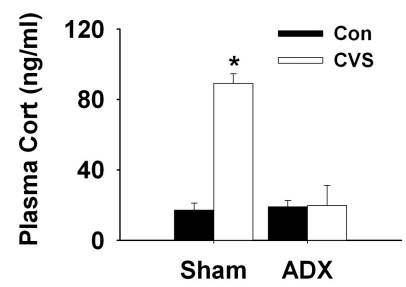

d

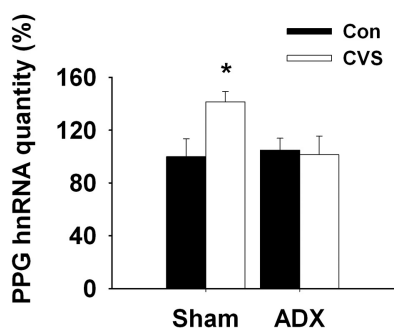

f

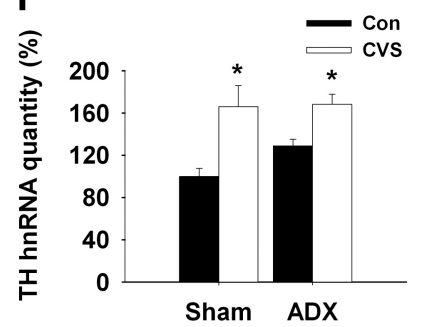

a

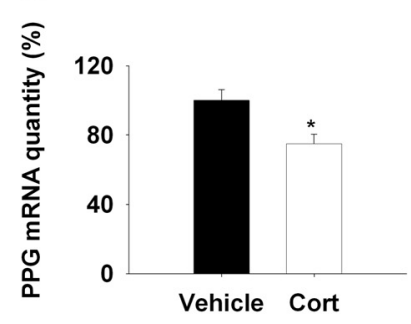

C

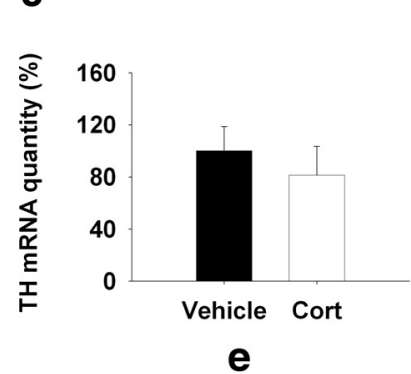

b

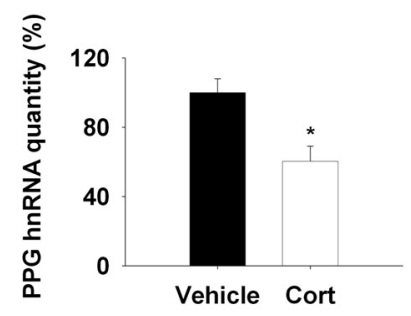

d

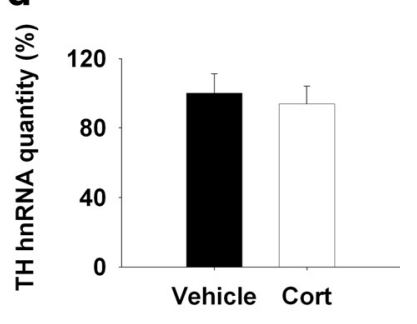

Figure 5. QRT-PCR analysis of the regulation of NTS PPG and TH transcription by CVS exposure in ADX-Cort-replaced rats. $\boldsymbol{a}$, Diurnal rhythms of plasma corticosterone was determined. ADX-Cort rats showed normal plasma corticosterone circadian as indicated by no difference for nadir and peak of plasma corticosterone between sham-ADX and ADX-Cort rats. $\boldsymbol{b}$, The basal plasma corticosterone was elevated by CVS exposure only in sham-ADX CVS rats. The prolonged stress challenge did not affect the basal plasma corticosterone in ADX-Cort rats. $\boldsymbol{c}, \boldsymbol{d}$, CVS exposure enhanced PPG mRNA degradation and PPG hnRNA expression in sham-ADX rats. There was no difference for PPG mRNA and hnRNA expression between unstressed and stressed ADX-Cort rats. $\boldsymbol{e}, \boldsymbol{f}$, Expression of TH mRNA and hnRNA were elevated by the 2 weeks CVS of exposure in both sham-ADX and ADX-Cort rats. ${ }^{*} p<0.01$ versus control (Con).

degradation, perhaps via interactions with RNA-binding proteins (Dhawan et al., 2007; Ishmael et al., 2008), suggesting a possible means for long-term destabilization of PPG mRNA, even in the face of enhanced transcription. In addition, glucocorticoids may promote transcription of RNA-binding proteins or perhaps microRNAs that specifically target PPG mRNA for enhanced degradation (Ing, 2005; Hobert, 2007; Rainer et al., 2009). Of note, the $3^{\prime}$ - untranslated region of PPG mRNA has recognition sequences for known microRNA species (Zhang et al., 2009).

Interestingly, exogenous corticosterone decreased PPG hnRNA, which was an effect opposite that observed as a consequence of CVS. However, as demonstrated in the ADX animals, this latter effect was dependent on stimulated release of adrenal products. The divergent effects of CVS and of stress-free glucocorticoid administration suggest that neural and hormonal events associated with stress in the context of elevated corticosterone are sufficient to enhance PPG transcription, whereas elevated corticosterone in the absence of stress signals has an opposite action.

In contrast to the observed effects on PPG mRNA, chronic stress increased TH mRNA expression and transcription in a glucocorticoid-independent manner. Coupled with our previous observations documenting enhanced dopamine $\beta$-hydroxylase innervation of PVN corticotropin-releasing hormone neurons

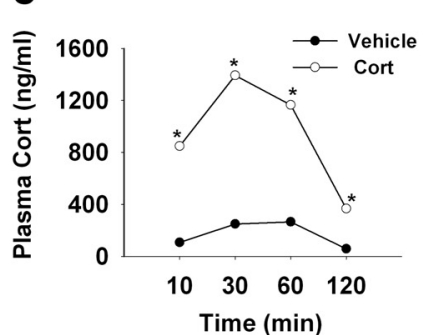

Figure 6. $\quad$ QRT-PCR analysis of the regulation of NTS PPG and TH transcription by chronic subcutaneous administration of corticosterone $(3.5 \mathrm{mg} / \mathrm{kg}) . \boldsymbol{a}, \boldsymbol{b}$, Chronic injection of corticosterone decreased PPG mRNA and hnRNA expression compared with the vehicle treatment. $\boldsymbol{c}, \boldsymbol{d}$, Chronic corticosterone injection did not affect the NTS TH gene expression. $\boldsymbol{e}$, The plasma corticosterone level was increased by acute subcutaneous injection of corticosterone at $10 \mathrm{mim}$, reached the peak at $30 \mathrm{~min}$, and maintained elevated levels at 60 and $120 \mathrm{~min}$ compared with the vehicle injection. ${ }^{*} p<0.05$ versus control.

(Flak et al., 2009), the data suggest that chronic stress increases the capacity of NE/E activation in critical stress-integrative pathways. Upregulation of TH mRNA in response to CVS appears to be particularly robust in cell groups rostral to the obex, corresponding to the region containing the majority of psychogenic stress-activated, PVN-projecting NE/E neurons (Dayas et al., 2001). Thus, stress upregulation is likely dependent on chronic drive of stress effector pathways projecting to the NTS.

Our data are consistent with previous studies documenting chronic stress-induced increases in TH mRNA expression in other stress models. For example, chronic stress exposure enhances expression of TH mRNA in the locus ceruleus, sympathetic ganglia, and adrenal medulla (cf. Sabban and Kvetnansky, 2001), suggesting that paradigms promoting sympathoadrenal activation produce generalized activation across multiple NE/E systems. In addition, previous studies demonstrate that both acute and chronic stress-related increases in locus ceruleus TH mRNA expression are independent of glucocorticoid secretion (Smith et al., 1991; Makino et al., 2002). These data suggest that chronic stress-induced changes in TH mRNA are refractory to glucocorticoid influence in other stress-regulated regions as well.

The corticosterone replacement and administration regimens used in this study were designed to emulate normal diurnal corticosterone secretion (in ADX rats) and twice-daily stress responses, respectively. We were able to demonstrate normal A.M. 
and P.M. corticosterone levels in ADX rats by providing the corticosterone in the drinking saline, in a manner similar to that observed by Jacobson and colleagues (Akana et al., 1985; Jacobson et al., 1990). After an initial surgery-related weight loss, weight gain in ADX-replaced rats paralleled that of sham controls. Thus, the ADX-Cort replacement regimen was sufficient to produce normal daily glucocorticoid secretion without mounting the glucocorticoids release under the stress stimulation. However, PPG mRNA expression was reduced in ADX-Cort-replaced animals relative to the controls, suggesting that corticosterone replacement does not completely compensate for the effects of adrenal removal on the NTS PPG.

Twice-daily corticosterone administration produced corticosterone pulses similar in character to those seen after twice-daily acute stress exposure in our CVS regimen. Notably, twice-daily corticosterone elicited thymic atrophy, confirming the cumulative efficacy of the corticosterone administration. In addition, significant retardation of weight gain was observed with chronic corticosterone exposure, a phenomenon also observed after chronic stress exposure in a variety of models, implicating glucocorticoids in stress-induced hypophagia.

Both GLP-1 and catecholamines activate stress effector pathways in the brain, including the HPA axis (Plotsky et al., 1989; Kinzig et al., 2003) and the sympathethic nervous system (Yamamoto et al., 2002). Concurrent glucocorticoid-dependent downregulation of PPG and glucocorticoid- independent increment of NE/E biosynthetic capacity and availability suggests that chronic stress downregulates one stress-excitatory pathway (GLP-1) while upregulating another (NE/E). On this basis, we postulate two very different roles for the two systems in stress adaptation. In the case of GLP-1, our previous studies indicate that chronic GLP-1 receptor blockade inhibits CVS-induced HPA axis hyperactivity, whereas GLP-1 supplementation exacerbates the impact of CVS on HPA axis sensitization and cumulative corticosterone exposure (as inferred from decrements in thymus weight) (Tauchi et al., 2008b). Given the stress-excitatory role of GLP-1 in CNS, the glucocorticoid-dependent reduction in GLP-1 suggests a role for glucocorticoids in negative feedback regulation via the NTS. Thus, downregulation of GLP-1 signaling may represent corticosterone-initiated adaptive mechanism involved in stress habituation.

In contrast to the GLP-1 system, CNS NE is involved in sensitization of chronic stress responses at several levels of the neuraxis, including the PVN. Although chronic stress results in tonic elevations in plasma corticosterone, the HPA axis in stressed rats usually exhibits full responsiveness to new, acutely applied stress. It is known that exposure to a previous stressor can facilitate the actions of a second stressor (Akana et al., 1992). Thus, upregulation of NTS NE/E systems may serve to permit the animal to respond to novel threats in the face of concurrent chronic stress, providing a sensitization mechanism to insure that the organism can rise to meet new physiologic challenges. The $\mathrm{NE} / \mathrm{E}$ system acts as a mechanism to insure that stress-induced, endogenous corticosterone feedback signals do not completely inhibit the HPA axis tone. Thus, it seems appropriate that the CVS-enhanced NE/E expression is independent of the chronic stress-induced glucocorticoids, to preserve stress responsiveness in the face of chronically elevated corticosterone levels.

Overall, our study supports a differential role for PPG and $\mathrm{NE} / \mathrm{E}$ systems in the management of responses to chronic stress. Stress-related disease states, such as depression and posttraumatic stress disorder, are known to be accompanied by dyshomeostasis in hormonal and autonomic stress effector pathways
(Carroll et al., 1976; Kathol et al., 1989; Barefoot et al., 1996). Our data suggest that imbalance of stress habituation and sensitization inputs arising from brainstem stress relays may play a role in regulating onset and/or severity of stress-related disease processes.

\section{References}

Ahima RS, Harlan RE (1990) Charting of type II glucocorticoid receptorlike immunoreactivity in the rat central nervous system. Neuroscience 39:579-604.

Akana SF, Cascio CS, Shinsako J, Dallman MF (1985) Corticosterone: narrow range required for normal body and thymus weight and ACTH. Am J Physiol 249:R527-R532.

Akana SF, Dallman MF, Bradbury MJ, Scribner KA, Strack AM, Walker CD (1992) Feedback and facilitation in the adrenocortical system: unmasking facilitation by partial inhibition of the glucocorticoid response to prior stress. Endocrinology 131:57-68.

Barefoot JC, Helms MJ, Mark DB, Blumenthal JA, Califf RM, Haney TL, O'Connor CM, Siegler IC, Williams RB (1996) Depression and longterm mortality risk in patients with coronary artery disease. Am J Cardiol 78:613-617.

Carroll BJ, Curtis GC, Mendels J (1976) Neuroendocrine regulation in depression. II. Discrimination of depressed from nondepressed patients. Arch Gen Psychiatry 33:1051-1058.

Collie NL, Walsh JH, Wong HC, Shively JE, Davis MT, Lee TD, Reeve JR Jr (1994) Purification and sequence of rat oxyntomodulin. Proc Natl Acad Sci U S A 91:9362-9366.

Dallman MF, Pecoraro N, Akana SF, La Fleur SE, Gomez F, Houshyar H, Bell ME, Bhatnagar S, Laugero KD, Manalo S (2003) Chronic stress and obesity: a new view of "comfort food." Proc Natl Acad Sci U S A 100:11696-11701.

Dayas CV, Buller KM, Crane JW, Xu Y, Day TA (2001) Stressor categorization: acute physical and psychological stressors elicit distinctive recruitment patterns in the amygdala and in medullary noradrenergic cell groups. Eur J Neurosci 14:1143-1152.

Dhawan L, Liu B, Blaxall BC, Taubman MB (2007) A novel role for the glucocorticoid receptor in the regulation of monocyte chemoattractant protein-1 mRNA stability. J Biol Chem 282:10146-10152.

Flak JN, Ostrander MM, Tasker JG, Herman JP (2009) Chronic stressinduced neurotransmitter plasticity in the PVN. J Comp Neurol 517:156-165.

Gaillet S, Lachuer J, Malaval F, Assenmacher I, Szafarczyk A (1991) The involvement of noradrenergic ascending pathways in the stress-induced activation of ACTH and corticosterone secretions is dependent on the nature of stressors. Exp Brain Res 87:173-180.

Geerling JC, Kawata M, Loewy AD (2006) Aldosterone-sensitive neurons in the rat central nervous system. J Comp Neurol 494:515-527.

Herman JP, Cullinan WE (1997) Neurocircuitry of stress: central control of the hypothalamo-pituitary-adrenocortical axis. Trends Neurosci 20:78-84.

Herman JP, Adams D, Prewitt C (1995) Regulatory changes in neuroendocrine stress-integrative circuitry produced by a variable stress paradigm. Neuroendocrinology 61:180-190.

Hobert O (2007) miRNAs play a tune. Cell 131:22-24.

Huo L, Grill HJ, Bjorbaek C (2006) Divergent regulation of proopiomelanocortin neurons by leptin in the nucleus of the solitary tract and in the arcuate hypothalamic nucleus. Diabetes 55:567-573.

Ing NH (2005) Steroid hormones regulate gene expression posttranscriptionally by altering the stabilities of messenger RNAs. Biol Reprod 72:1290-1296.

Ishmael FT, Fang X, Galdiero MR, Atasoy U, Rigby WF, Gorospe M, Cheadle C, Stellato C (2008) Role of the RNA-binding protein tristetraprolin in glucocorticoid-mediated gene regulation. J Immunol 180:8342-8353.

Jacobson L, Sharp FR, Dallman MF (1990) Induction of fos-like immunoreactivity in hypothalamic corticotropin-releasing factor neurons after adrenalectomy in the rat. Endocrinology 126:1709-1719.

Kathol RG, Jaeckle RS, Lopez JF, Meller WH (1989) Pathophysiology of HPA axis abnormalities in patients with major depression: an update. Am J Psychiatry 146:311-317.

Kinzig KP, D'Alessio DA, Seeley RJ (2002) The diverse roles of specific GLP-1 receptors in the control of food intake and the response to visceral illness. J Neurosci 22:10470-10476.

Kinzig KP, D’Alessio DA, Herman JP, Sakai RR, Vahl TP, Figueredo HF, 
Murphy EK, Seeley RJ (2003) CNS glucagon-like peptide-1 receptors mediate endocrine and anxiety responses to interoceptive and psychogenic stressors. J Neurosci 23:6163-6170.

Larsen PJ, Tang-Christensen M, Holst JJ, Orskov C (1997) Distribution of glucagon-like peptide- 1 and other preproglucagon-derived peptides in the rat hypothalamus and brainstem. Neuroscience 77:257-270.

Liposits Z, Sherman D, Phelix C, Paull WK (1986) A combined light and electron microscopic immunocytochemical method for the simultaneous localization of multiple tissue antigens. Tyrosine hydroxylase immunoreactive innervation of corticotropin releasing factor synthesizing neurons in the paraventricular nucleus of the rat. Histochemistry 85:95-106.

Livak KJ, Schmittgen TD (2001) Analysis of relative gene expression data using real-time quantitative PCR and the 2(-delta delta $\mathrm{C}(\mathrm{T})$ ) method. Methods 25:402-408.

Makino S, Smith MA, Gold PW (2002) Regulatory role of glucocorticoids and glucocorticoid receptor mRNA levels on tyrosine hydroxylase gene expression in the locus coeruleus during repeated immobilization stress. Brain Res 943:216-223.

Marti O, Gavalda A, Gomez F, Armario A (1994) Direct evidence for chronic stress-induced facilitation of the adrenocorticotropin response to a novel acute stressor. Neuroendocrinology 60:1-7.

Paxinos G, Watson C (2005) The rat brain in stereotaxic coordinates. New York: Elsevier Academic.

Plotsky PM (1987) Facilitation of immunoreactive corticotropin-releasing factor secretion into the hypophysial-portal circulation after activation of catecholaminergic pathways or central norepinephrine injection. Endocrinology 121:924-930.

Plotsky PM, Cunningham ET Jr, Widmaier EP (1989) Catecholaminergic modulation of corticotropin-releasing factor and adrenocorticotropin secretion. Endocr Rev 10:437-458.

Rainer J, Ploner C, Jesacher S, Ploner A, Eduardoff M, Mansha M, Wasim M, Panzer-Grumayer R, Trajanoski Z, Niederegger H, Kofler R (2009) Glucocorticoid-regulated microRNAs and mirtrons in acute lymphoblastic leukemia. Leukemia 23:746-752.

Ritter S, Watts AG, Dinh TT, Sanchez-Watts G, Pedrow C (2003) Immunotoxin lesion of hypothalamically projecting norepinephrine and epinephrine neurons differentially affects circadian and stressor-stimulated corticosterone secretion. Endocrinology 144:1357-1367.

Rozen S, Skaletsky H (2000) Primer3 on the WWW for general users and for biologist programmers. Methods Mol Biol 132:365-386.

Sabban EL, Kvetnansky R (2001) Stress-triggered activation of gene expression in catecholaminergic systems: dynamics of transcriptional events. Trends Neurosci 24:91-98.

Sarkar S, Fekete C, Legradi G, Lechan RM (2003) Glucagon like peptide-1 (7-36) amide (GLP-1) nerve terminals densely innervate corticotropin- releasing hormone neurons in the hypothalamic paraventricular nucleus. Brain Res 985:163-168.

Sawchenko PE, Swanson LW (1981) Central noradrenergic pathways for the integration of hypothalamic neuroendocrine and autonomic responses. Science 214:685-687.

Schulkin J, McEwen BS, Gold PW (1994) Allostasis, amygdala, and anticipatory angst. Neurosci Biobehav Rev 18:385-396.

Schwaber JS, Kapp BS, Higgins GA, Rapp PR (1982) Amygdala and basal forebrain direct connections with the nucleus of the solitary tract and the dorsal motor nucleus. J Neurosci 2:1424-1438.

Smith MA, Brady LS, Glowa J, Gold PW, Herkenham M (1991) Effects of stress and adrenalectomy on tyrosine hydroxylase mRNA levels in the locus ceruleus by in situ hybridization. Brain Res 544:26-32.

Szafarczyk A, Malaval F, Laurent A, Gibaud R, Assenmacher I (1987) Further evidence for a central stimulatory action of catecholamines on adrenocorticotropin release in the rat. Endocrinology 121:883-892.

Tauchi M, Zhang R, D’Alessio DA, Stern JE, Herman JP (2008a) Distribution of glucagon-like peptide-1 immunoreactivity in the hypothalamic paraventricular and supraoptic nuclei. J Chem Neuroanat 36:144-149.

Tauchi M, Zhang R, D’Alessio DA, Seeley RJ, Herman JP (2008b) Role of central glucagon-like peptide-1 in hypothalamo-pituitary-adrenocortical facilitation following chronic stress. Exp Neurol 210:458-466.

Uht RM, McKelvy JF, Harrison RW, Bohn MC (1988) Demonstration of glucocorticoid receptor-like immunoreactivity in glucocorticoid-sensitive vasopressin and corticotropin-releasing factor neurons in the hypothalamic paraventricular nucleus. J Neurosci Res 19:405-411:468-409.

Ulrich-Lai YM, Herman JP (2009) Neural regulation of endocrine and autonomic stress responses. Nat Rev Neurosci 10:397-409.

Ulrich-Lai YM, Figueiredo HF, Ostrander MM, Choi DC, Engeland WC, Herman JP (2006) Chronic stress induces adrenal hyperplasia and hypertrophy in a subregion-specific manner. Am J Physiol Endocrinol Metab 291:E965-E973.

Vertes RP (2004) Differential projections of the infralimbic and prelimbic cortex in the rat. Synapse 51:32-58.

Yamamoto H, Lee CE, Marcus JN, Williams TD, Overton JM, Lopez ME, Hollenberg AN, Baggio L, Saper CB, Drucker DJ, Elmquist JK (2002) Glucagon-like peptide-1 receptor stimulation increases blood pressure and heart rate and activates autonomic regulatory neurons. J Clin Invest 110:43-52.

Young EA, Kwak SP, Kottak J (1995) Negative feedback regulation following administration of chronic exogenous corticosterone. J Neuroendocrinol 7:37-45.

Zhang R, Packard BA, Tauchi M, D’Alessio DA, Herman JP (2009) Glucocorticoid regulation of preproglucagon transcription and RNA stability during stress. Proc Natl Acad Sci U S A 106:5913-5918. 